\title{
ESCEPTICISMO Y FILOSOFÍA EN JORGE LUIS BORGES
}

\author{
MARCOS SANTOS GÓMEZ \\ Universidad de Granada
}

\begin{abstract}
RESUMEN: Se presenta y discute la polémica perspectiva filosófica existente en la obra de J. L. Borges. Fundamentalmente, el escritor juega a partir de un irónico y conmovedor escepticismo que lo vincula con planteamientos como la hermenéutica, la intertextualidad y el pensamiento de la diferencia (Derrida). Se lo ha relacionado, también, con formas de estructuralismo y con la disolución del sujeto y las identidades.
\end{abstract}

PALABRAS CLAVE: Derrida; escepticismo; hermenéutica; intertextualidad; J. L. Borges; literatura; postmodernidad; subjetivismo.

\section{Skepticism and Philosophy in Jorge Luis Borges}

ABSTRACT: We present and discus the controversial philosophical view which is in the work of J. L. Borges. Fundamentally, the writer plays from an ironic and poignant skepticism that links to approaches such as hermeneutics, intertextuality and the thought of the difference (Derrida). He has been associated also with forms of structuralism and with the dissolution of the subject and identities.

KEY WORDS: Derrida; skepticism; hermeneutics; intertextuality; JL Borges; literature; postmodernism; subjectivism.

\section{La Relación de Borges con la filosofía}

Uno de los tópicos sobre Borges, que se ha discutido a menudo, es si éste es antes autor literario o filósofo ${ }^{1}$. Con M. Schultz cabe, juiciosamente, preguntar en relación con la filosofía en Borges: «¿Qué validez tiene el tratamiento lírico de la filosofía? ¿Es acaso una mera versión menos analítica y desarrollada de los asuntos filosóficos? ¿Hay algo así como un plus de intensidad que se gana con la forma lírica en cuanto a expresión de los problemas filosóficos?» (M. Schultz 1992, p. 110). Quizás ambas, literatura y filosofía, se esfuerzan por ser cauce de un decir el mundo. «filosofía y literatura "dicen" el mundo,

1 Cuestión que recoge y expone Lema-Hincapie (2002), quien menciona las distintas respuestas dadas a ella. Oscilan desde una decidida negación de la filosofía en Borges, hasta quienes le atribuyen con claridad una producción filosófica. Resulta interesante la perspectiva de los muchos que se sitúan en el término medio entre ambos extremos, que aportan interesantes matices a la cuestión. De esta opción intermedia, nosotros aquí resaltamos cómo los textos de Borges aportan una inquietud por la realidad del mundo, que le conduce a practicar órdenes y desórdenes simultáneos como táctica, en el mundo y en su/ la escritura. Esto podría ser, nos parece, una opción literaria que afecta a la filosofía. Ambas, filosofía y literatura, abordan el problema de la realidad del universo y de la posibilidad o imposibilidad de expresarla. Será este aspecto «desorientador» y nihilizante de los textos borgeanos, entre filosofía y literatura, lo que apunta a una cosmovisión escéptica, que vamos a exponer en el presente trabajo. 
producen sentido es decir, orientación, afección, crítica, verdad, significado» (Camauer 2009, p. 144). Según esto, sería posible estimar que existe un nexo entre ambas, filosofía y literatura, que se muestra a lo largo de la producción borgeana. Pensar sobre este tópico del autor argentino nos puede ayudar a perfilar cuándo y por qué una filosofía haya de encontrar expresión poética o cuándo una literatura pueda hallar en la filosofía su tema. Será la interconexión entre ambas, al menos en la producción de Borges, de lo que vamos a escribir en las líneas que siguen².

Digamos que la elegante prosa que se extiende bellamente con ritmo pausado en las creaciones de Borges tiene como principal objeto, en la mayoría de los casos, o sea, como tema literario y de especulación, las más sutiles elucubraciones de la filosofía, la teología e incluso las matemáticas. Cabe afirmar, con Camauer, que «La obra de Borges desafía los límites estrictos que pueden establecerse entre los géneros puesto que sus ficciones y poesías expresan filosóficamente el mundo» (Camauer 2009, p. 145). Tanto los poemas como los ensayos y cuentos más célebres, introducen un inquietante escepticismo en el alma al tomarse como un juego los distintos sistemas filosóficos o la ciencia. Este juego es ya una opción filosófica.

$\mathrm{Si}$ es necesario colocarle una etiqueta, podemos considerar a Borges un escéptico, o tal vez un pesimista que afirma no creerse demasiado el mundo y que opone al horror de lo caótico su elegante ironía ${ }^{3}$. Es precisamente ese aspecto irónico, apacible, elegante lo que Borges construye como una cierta positividad que lo libra del permanecer siempre en el momento más nihilista y destructivo del escepticismo (Castany 2005). Tanto en su momento más ético y tolerante, como en su negación más destructiva, Borges emprende una estética del escepticismo. Desde luego, no cree demasiado en las filosofías que desarrolla

2 Hay otra función de la poesía para la filosofía, en Borges, señalada por McDermid (2005), por la que la poesía incita a la emoción y al asombro ante el mundo, que deben preceder a toda filosofía y que antecede, en particular, al sistema platónico. Ciertamente, nos enseña a conmocionarnos ante mundo y filosofía. Pero lo que expondremos en el presente trabajo llega mucho más lejos. Como abundantes comentadores y autores han resaltado, es en la medida en que el ser maravillado por el mundo no antecede, en Borges, a una filosofía realista o idealista que describa la realidad con cierta claridad u orden. El asombro borgeano lo es por el desorden que vence posteriormente a todo humano empeño de crear un orden. El pasmo se da en el vertiginoso juego de los órdenes y los desórdenes al que nos referiremos más adelante. Queda así el asombro como emoción que anticipa y revierte en el juego de componer y pulverizar lo real.

3 En algunos elementos de su obra, quizás en relación lejana con su escepticismo, Borges parece también aproximarse al punto de vista pragmatista, en lo que éste tiene de anti-idealismo y «debilidad» ontológica. Así lo recoge, en su trabajo Bosteels (2007). Este autor, no obstante, parece escribir con el empeño de ensalzar las bondades del pragmatismo norteamericano, al que contrapone el pensamiento continental europeo de la diferencia. Por esto mismo, relativiza el elemento más puramente postmoderno que hubiere en Borges. En el presente trabajo nos centramos, sin embargo, en las conexiones de Borges con el pensamiento continental más postmoderno y dejamos para otro momento la discusión sobre Borges y el pragmatismo. 
en sus obras, en cuanto a su poder referencial. De ellas, destila finalmente sólo lo literario como verosímil, la propia expresión como núcleo de lo expresado. Señala Magnavacca «El escepticismo sobre una filosofía ha mutado en fe literaria» (Magnavacca 2007, p. 83); y en retórica, apabullante erudición o acumulación de citas que expresan aun más escepticismo. La de Borges es una palabra dicha dentro de una tradición y estilo clásicos que sirven para realzar el imposible al que dudosamente refieren ( $\mathrm{a}$ un orden que en realidad es desorden y apunta al mismo), su desarticulación con el mundo, un mundo hecho de pliegues y melancolías barrocas, que son captadas por Borges, contrastivamente, en una estética neoclásica. Un pensamiento, en cualquier lugar, que se expresa en lo bello, como cosa bella. El universo es en cuanto es bello, para Borges, con una belleza que antecede y somete al logos, al decir razonable, que lo suplanta:

Esta opción por la belleza antes que por la verdad constituye una de las claves de la apertura de Borges hacia filosofías contradictorias, la permanente ambigüedad en torno de su propia posición. Hay en Borges un deliberado abandono de la pretensión de conocer la realidad misma, debido a su descreimiento en tal posibilidad (Zavadivker 2008, p. 2).

Una opción por la belleza, que es persuasión por simulacros, lengua sin significado que recurre a paradojas. Una belleza elocuente, performativa, creadora de mundos. Para Borges, un sistema filosófico gusta, vale por su belleza. Y es bello porque activa la simulación que hace mundos, practicando una retórica o elocuencia del decir sustractivo (al modo de la teología negativa) o, por el contrario, de un apabullante y sumativo apilar textos. La razón y los sistemas han de vivenciarse como objetos bellos para que manifiesten lo que quieren decir. Como indica Zavadivker, para Borges: «El mejor modo para captar ciertas ideas consiste en hacerlas vivenciales e intuitivas, no en argumentar a favor de ellas» (Zavadivker 2008, p. 4).

En esta reconstrucción deconstructiva del mundo, se precisa de una memoria poblada de recuerdos vacíos, que valen por su forma, como la vacilante memoria de un ciego que suple a sus ojos, sin referentes. Una memoria que es, también, la de las tradiciones literarias, que es lo único que, según Borges, nos aúpa de la nadería que es el yo singular (Borges 1998)4. Se trata de una forma

4 Borges practica esa disolución de identidad y sujeto en sí mismo, como hombre y como autor, por diversos procedimientos, como puede rastrearse en los textos comentados e interpretados de este modo por Premat (2003).También se ha señalado el paralelismo entre técnicas expresivas de disolución del yo empleadas por Nietzsche y por Borges: (CAMAuER 2007, pp. 147-148). Se da, pues, en Borges (y otros autores, como Cervantes), una disolución del personaje de la obra literaria que acaba afectando a la identidad del sujeto real que lo escribe, que también parece disolverse. El ataque literario a la vieja unidad del personaje en una narración, curiosamente tiene consecuencias en la constitución de la realidad. Lo que se plantea literariamente, desafía y ficcionaliza toda la realidad. «From Cervantes to Borges the process of the disappearing hero in literature is unmistakable. Nevertheless that decline has paradoxically coincided with an increase in self-curiosity that ranges from fascination to scorn. The preoccupation with self has brought author and characters psychologically closer together and has subtly provoked a sharper critical view of reality» (EARLE 2003, p. 12). 
de salvación por el incierto recuerdo no exenta desde luego de precariedad. Es memoria narrada de una tradición que se reescribe constantemente, pero que aporta la ilusión de la continuidad y la identidad. La identidad se construye narrativamente ${ }^{5}$, del mismo modo que historia o mundo. Memoria que está compuesta, también de olvidos y de inanidades, como prueba el contraejemplo grotesco de «Funes el memorioso» (Amaro 2005, p. 190). Como señala J. R. Sagastume a partir del relato «El inmortal» (2011, p. 274):

Sólo podemos decir que un sujeto dice o hace esto o aquello en la narración, pero no podemos establecer definitivamente quién es el autor de la acción; el sujeto siempre se escurre. Y en parte se escurre a causa de la falibilidad del lenguaje; en parte, a causa de la falibilidad de la memoria del narrador. El relato se convierte así en un juego de ideas articuladas en diversos vocabularios que nos lleva a reflexionar, como se ha propuesto, sobre la imposibilidad de alcanzar un vocabulario final que pueda establecerse como normativo a la hora de definir el yo.

Cae la normatividad. A las cosas se accede, siempre relativamente, con la redescripción. El lenguaje es algo contingente, no apto para captar absolutos como la identidad del sujeto o, hemos señalado, Dios o el propio mundo. Tampoco para fundar una libertad (Urroz 2005). Esta imposibilidad para decir totalmente o pensar cualquier unidad, ya sea el sujeto, Dios o el universo, con el esfuerzo, sin embargo, de decirlo o sugerirlo, es lo que subyace a todo Borges ${ }^{6}$.

La inquietud que Borges introduce en el lector le hace a éste experimentar un "vértigo metafísico», una rara sensación que se cuela como fisura en la ilusión que es el todo y que acaba impugnándolo, mostrándolo en su precariedad y contingencia. Dice el escritor porteño, tras proferir la que puede ser la más caótica y genial enumeración de la historia de la literatura, en el relato «El Aleph» (que con la relación de unas pocas singularidades, pretende enumerarlo todo, o enumerar lo innumerable):

5 Ésta es, indica Presas (1999), la apuesta filosófica fundamental de Borges: el sujeto disuelto en la narratividad, y la narración como relativo acceso a lo imposiblemente «real». Resulta evidente que esto, como otros elementos que vamos a tratar, ubica a Borges en un lugar cercano a las filosofías más postmodernas. Esto pugna con posiciones ilustradas, como por ejemplo la de Kant, en torno a la estética, de la que niega todo poder explicativo. Lo literario y lo estético, para Borges, abren (cuentan) mundo y exploran nuevas posibilidades (narraciones) de relación entre los hombres y el mundo o los otros hombres. En cada relectura se recorre un mismo mundo pero diferente y singular.

6 Esto se manifiesta especialmente en la traducción, tarea también inagotable e ineludiblemente inexacta (aunque no imposible), que opera sobre la obra y sus nexos intertextuales, sobre el texto en cuanto texto y en función de otros textos (el original, las múltiples traducciones, la bibliografía secundaria), que desborda al plano y conocimiento del autor como tal. La traducción es, en Borges, el paradigma de la lectura. Sobre los tópicos borgeanos en torno a la labor traductora, tenemos el trabajo de Jill Levine (2012), basado en los pocos pero relevantes escritos que Borges dedicó al tema. Para nosotros, de estas obras, destaca «Pierre Menard, autor del Quijote»(Borges 2002). 
y sentí vértigo y lloré, porque mis ojos habían visto ese objeto secreto y conjetural, cuyo nombre usurpan los hombres, pero que ningún hombre ha mirado: el inconcebible universo (Borges 1999, p. 194).

Borges enseña, con asombrosos malabarismos literarios, a saborear la filosofía del mismo modo como se saborea un buen poema. Lo cual llega a convertirse en tomar, como hemos indicado, a la filosofía como objeto estético. Esto asume de manera subyacente e implícita un potente escepticismo ante la filosofía, que se expresa en el cultivo y desarrollo fruitivo de sistemas filosóficos en los que no se cree:

Como otros poetas, Borges ensaya una comprensión del mundo en su literatura nutrida de modo eminente, entre otras concepciones, de la visión propia del neoplatonismo medieval. Se trata, sin embargo, de un intento desesperado que acaba en decepción, en la certeza de que esos textos neoplatónicos forman parte de lo fantástico, de aquello en lo que se quisiera creer, sin conseguirlo (Magnavacca 2007, p. 82).

Hemos constatado la evidencia de un raro esplendor del mundo en el que relucen, reveladoramente, sus límites, en la poesía y relatos del escritor Jorge Luis Borges. El que él mismo considerara su mejor poema se llama, precisamente, «Límites». Encuentra el autor argentino en las cosas, y en él mismo, esa gravedad hacia la nada que puede manifestar cualquier objeto cotidiano, como si en lo corriente o en lo objetivo se escondiera la verdad conmovedora de una nada. Manifiesta su poesía esta precariedad de todo lo existente. Camauer (2009) señala la coincidencia de estos elementos borgeanos con el segundo Heidegger, en cuanto que ambos entienden toda referencia (acto, lenguaje o razón referentes a un mundo objetivo) como un fracaso; pero, paradójicamente, es en el pronunciar palabras poético como se insinúa, sustractivamente, la verdad. En esto, no habría, según Camauer, una diferencia esencial entre Heidegger y Borges, entre literatura y filosofía.

Las enseñanzas de Heidegger y Borges nos ponen en el camino de la paradójica 'precisión significativa' y referencial que tanto filosofía como literatura son capaces de realizar: la revelación del lenguaje es, precisamente, la inminencia de una revelación: sentido que se funda pero por alusión, por asociación y sustracción de significado pleno (Camauer 2009, p. 155).

Para Borges, como para el budismo o Schopenhauer, el mundo (fenoménico) es ilusorio, irreal y tiende constantemente a la nada. Alberga su estigma. Su magia de artista es mostrarlo claramente en los objetos y en los empeños y en las inventadas trascendencias de los hombres. Aun más, para concluir, cabe aseverar que «Al restar valor a la filosofía como dogma que permite entender el universo por completo, ha constituido un nuevo camino que impone la reconsideración de viejos problemas olvidados» (Báez 2003, p. 4). Una filosofía que recupere su carácter de apuesta y convicción, de fe o secta filosófica, en la que los sistemas se vivencien, en la que la filosofía sea elocuente como belleza. Algo no del todo ajeno a la expresión filosófica anterior a la modernidad (Castany 2005) que con Borges queda, para mal o para bien, recuperado. 


\section{El escepticismo de Borges}

El paradigma moderno presupone, por un lado, la existencia de hechos considerados datos puros que existen sin contradicción en la naturaleza y que, por otro lado, pueden ser captados por parte de un sujeto en forma de reflejos que coinciden con el modelo. Hay, por eso, un cierto rechazo de gran parte de la tradición moderna al escepticismo filosófico (Castany 2005). Borges gustaba de releer autores considerados escépticos, con un fuerte momento crítico y destructivo, nihilizante. Para ellos se dan limitaciones tanto en el supuesto sujeto que capta la realidad, como en la captación posible de un objeto que es inabarcable e ilimitado.

Pero frente a ellos, en la modernidad, todo alude a la identidad de un hecho consigo mismo, en su consistencia, que permite captarlo como un todo por una razón que se acopla identificativamente a los hechos. Tanto la filosofía analítica (Frege) como la fenomenología husserliana ${ }^{7}$, a pesar de sus diferentes puntos de partida, coinciden en un cierto culto a los hechos, bien sea como datos puros de la experiencia (filosofía analítica, positivismo) o como datos puros de la conciencia intencional (fenomenología). En cualquier caso es posible una captación de lo real que puede expresar lo que es, sin fisuras. Así, incluso la fenomenología orbita en la antigua tradición de la metafísica occidental, ya que en medio de la aparente multiplicidad de los datos sensibles, concede que hay una mismidad o presencia que preexiste a todos los juicios posibles y que garantiza la fortaleza de la apariencia (Sartre). Pero ya Hume, un empirista querido por Borges, nos hace despertar de este sueño dogmático que es la fe en la identidad del yo disolviéndolo en acumulación de percepciones distintas. Una disolución de la personalidad por la que ésta es las percepciones, sin que exista un soporte de las mismas (Zavadivker 2008, p. 4).

7 Una cuestión interesante es la proximidad de Borges a la Fenomenología. En el "fenómeno" se dan dos polos: el objetivo y el subjetivo, que superan el binomio moderno entre el sujeto y el mundo de objetos. Objeto y conciencia se dan a una, en la intuición. Hay, además, como señala CofRé (1995), una estética fenomenológica que contra el psicologismo, convierte la estética en investigación ontológica u ontológica-existencial. La obra artística es, antes que objeto, una ficción dentro de una realidad que no es absoluta, como tanto se desarrolla en Borges. La obra de arte tiene una naturaleza óntica, es "algo» y se ejerce en ella una operación metafísica que lamina el mundo, que lo re-crea y re-define, en la percepción estética. De aquí que haya una abolición de la frontera entre realidad y ficción, más allá de lo meramente lúdico del juego borgeano, que aparece en Borges ampliamente, como tópico vinculado también con la Fenomenología, según Cofré (1995, pp. 335). Hay «nueva» realidad o «nuevo» ser en la obra artística. La creación artística e incluso intelectual incide (como aparece ampliamente en el relato «Tlön, Uqbar, Orbis Tertius») en el mundo, «haciendo» mundo. «(...) surge un cuento o una novela, como un todo complejo, integrado y coherente, como una suerte de estructura multiestratificada y polifónica que, la mirada intuitiva del lector, atraviesa sin dificultad para posarse en el mundo representado - por virtud del discurso ficcional- y considerarlo como pura ficción o fantasía y, de este modo, alcanzar la fruición estética y el goce espiritual que las grandes obras — como las de Borges- suelen tener» (COFRÉ 1995, pp. 339-340). 
En la situación propia del hombre, el ser es antecedido por la existencia, auténtica forma ésta del ser, un ser que es apariencia antes que esencia. Pero esto también se sustenta en una idea de unidad que caracteriza a todas las cosas y a todo lo que existe y que permite su captación. Esa unidad e identidad perfecta facilita que pueda ser captada, bien sea al modo fenomenológico o también como experiencia sensible en la tradición realista que derivó en el conocimiento como reflejo o captación intelectual de lo real a partir de la experiencia, cultivado por el positivismo lógico (Russell, Tractatus). Pero el supuesto e ideal de la posibilidad de un conocimiento uniforme es compartido, de un modo u otro, por toda la tradición filosófica, incluido el kantismo. Bien sea el sujeto que capta como un espejo o el sujeto que constituye a partir de la experiencia, o bien el sujeto de la conciencia intencional, siempre hay un mundo que captar.

La crisis de lo que podríamos denominar el pensamiento moderno de la identidad y de lo que se ha denominado «metafísica de la presencia», llega tras Nietzsche, sobre todo en la figura de Heidegger. A partir de aquí, ese presente puro del dato captable por el sujeto resulta una ilusión, pues lo que caracteriza al presente no es ya la identidad sino la diferencia. Porque el presente difiere de sí. Lejos de servir como fundamento para el conocimiento, la conciencia nos engaña, ya que percibe una identidad allí donde hay, por el contrario, una diferencia. Ésta es la base del pensamiento de la diferencia del filósofo Derrida, por lo que la conciencia que capta unidades, puede, lejos de garantizar la unidad del mundo, resultar una ilusión. El conocimiento se basaría en esta ilusión de que el mundo como un todo o bien en sus partes, se constituye por identidades, por unidades puras afirmativas y presenciales. Esto, en realidad, entronca ya con una tradición, también propia de la filosofía, de sospecha ante lo dado, de impugnación a la conciencia cuyos objetos pueden ser simulaciones o verdades parciales, falsas verdades que ocultan dobleces y recovecos (Freud, Nietzsche) o contradicciones (Marx).

El planteamiento crítico de Derrida, autor señero en la concepción del mundo como «diferencia» parte de otro autor: Saussure. Según el estructuralismo lingüístico, lo que define a un término ya no es su identidad con la realidad, con un objeto de la realidad (condiciones de verdad, en la expresión de Frege), sino sus acepciones convencionales dentro de una determinada lengua. «El significado no se confunde con el referente, o con el objeto designado, sino con una definición aceptada o convencional en el sistema de la lengua» (Scavino 2007, p. 30). Esto se pone muy de relieve en el relato «La biblioteca de Babel» (Borges 2002), que describe un universo compuesto de infinitas combinaciones de símbolos, destacando lo arbitrario de éstas y de la relación de los símbolos con la realidad, todo ello vinculado a tesis estructuralistas, según Radford (2005, pp. 68-69).

No es que existan sentidos distintos a partir de una realidad o referente, sino que hay sentidos a partir de sentidos, en una cadena interminable. Esto es ejemplificado por la comparación entre lenguas distintas que parecen suponer mundos distintos. Porque no hay una captación lingüística del mundo, fiel al 
mundo como último referente. Así, además de la pérdida del referente real o mundano, también ocurre que la propia identidad del signo es aparente, pues en todo signo o referente habitan otros signos o referentes, acaso antitéticos, que son traídos soterradamente a colación por la evocación del signo. Hay cadenas sintagmáticas en las que se ubican los signos, aun estando aparentemente aislados. Hay un pasado y unas sombras que acompañan a todo signo y que ponen en cuestionamiento su identidad. Hay también un futuro en el signo que implica que la cadena en la que se va transformando o deshaciendo es interminable, y siempre existirá la posibilidad de nuevos movimientos y sucesiones. Por eso, el sentido es algo perennemente diferido (Derrida 2007). Hay como una suerte de tendencia a fugarse de sí, a evadirse de sí mismo, en todos los signos, cuya afirmación e identidad aparentes disimulan que los constituyen un cúmulo entremezclado de divergencias y tensiones. Tal como lo entiende Derrida, esto va mucho más allá de, por ejemplo, Hegel, que aunque sitúa lo contrario (negación) como constituyente de la afirmación, en las cosas o en el concepto, continúa aceptando una cierta identidad en los momentos del sistema y en el propio todo o sistema como tal, que llega a ser una suerte de objeto mayor aunque contenga una sucesión de afirmaciones y negaciones. Lo importante es que para Derrida nunca se llega a un final, ni hay una suerte de ley general o metafísica que asuma todas las diferencias, sino que hay una mera sucesión sin forma de sentidos siempre en suspenso.

Se dan además otras consecuencias a partir del pensamiento de la diferencia. Deleuze, en su lectura de Borges, ya señalará esta disolución de lo real en la que se interrelacionan y confunden los ámbitos ficcional y real, que llegan a ser una única cosa. Señala, en relación con Deleuze y Borges, Tudela (2002, pp. 14):

Lo verdadero y lo falso, como lo real y lo imaginario, o simplemente lo real y lo irreal, entran en una zona de indiscernibilidad que entraña una superación de ambas series polares, ya que la falsedad no es el error, no es la confusión ni lo opuesto a lo verdadero, sino la potencia que hace indecidible la verdad, pues no se presenta como copia o imperfección del modelo, que ha desaparecido.

Otro autor que en algún momento toma como imagen a la creación borgeana, es Foucault. Lo que éste muestra de Borges es la capacidad de romper los vínculos del lenguaje representativo con la realidad que se supone representa, proceso que produce una disolución de ambos, en cuyos resquicios aparecen los guiños de otras realidades u órdenes posibles, de manera antes negativa que positiva. Escribe Sabot (2006, p. 43):

A través de estas formas radicales de la impugnación de los poderes de la representación y del discurso, la literatura [Borges] y la pintura modernas asumen, según Foucault, la función crítica de una experiencia de pensamiento que consiste en burlarse de las formas convencionales de esta representación, y hacer trabajar, los unos contra los otros las palabras y las cosas hasta que aparezca, bajo ellos, entre ellos, el no lugar que vuelve caduca e incierta toda nominación de lo visible. 
Retornando a Derrida, una consecuencia, decíamos, de su pensamiento de la diferencia es la preeminencia de la escritura sobre el habla, basada en que en la escritura resulta más patente que el significado de un significante ya no es un referente (la cosa misma) sino otro significante. Al contrario, el habla crea la ilusión de la identidad. «Cuando hablamos, (...) caemos en la ilusión metafísica de la referencialidad y de la univocidad: pensamos que existe una correspondencia, o una adecuación, entre las palabras y las cosas, entre los discursos y el mundo» (Scavino 2007, p. 34). Esta es la ilusión que Rorty va a denominar logocentrismo o filosofía de la representación; la de que el discurso o lenguaje supone «que el lenguaje puede reflejar las cosas tal cual son o tal como la percibió desinteresadamente una conciencia que mantendría una relación inmediata con la cosa, anterior a toda significación cultural o a todo lenguaje» (Scavino 2007, p. 34).

Una consecuencia de esto, es que no puede establecerse una distinción precisa entre el discurso unívoco de la ciencia y el discurso equívoco de la ficción (Scavino 2007, p. 35). Es en la medida en que ya no hay referencialidad en el lenguaje. Es lo mismo que percibimos en la obra de Borges. Su trato escéptico con el lenguaje. Esto se desata sobre todo en su época de madurez, la de los grandes relatos de los años 40. Como señala Lorena Amaro:

A través del cuento, descubre las aporéticas imposibilidades del lenguaje, antes sólo esbozadas en sus textos. A partir de este momento (...) el escritor pone en juego en sus textos lo que hasta ahora tan sólo había sido una intuición: su escepticismo ante las posibilidades comunicativas del lenguaje. (Amaro 2005, p. 184).

En este contexto, se hunde y explaya, podríamos decir, en una dimensión metafórica de las palabras. Para Borges, las verdades son ya metáforas que han dejado de tenerse como tales. El lenguaje es, siempre, metáfora.

De esta manera reconocemos el valor metafórico de todo sistema lingüístico y lo vemos como una útil herramienta que nos permite constantemente formular redescripciones de la realidad sin la necesidad de establecer un vocabulario final que sí causaría la cesación de la lengua (Sagastume 2011, p. 279).

No sólo el lenguaje,

Para el autor de El aleph el mundo es una larga metáfora donde nada es consistente, material o continuo, donde no hay sucesión temporal, y donde incluso decir 'yo' o 'existo' se vuelve una petición de principio, una ilusión o un solipsismo que de inmediato se disuelve en el anonimato de las voluntades que son todo menos voluntades (Urroz 2005, p. 83).

Pero en cuanto al lenguaje, fabricante o descubridor de grietas que pueblan el dudoso mundo, es su limitación, tratada y desarrollada literariamente, en la modulación de las pocas metáforas que imposible o precariamente nos dicen, donde se puede sugerir un cierto absoluto en la ilación entre las innumerables enumeraciones y descripciones que torpemente emprendemos (Sagastume 
2011, p. 288). Es decir, se da una verdad, en cuanto imagen fluctuante del mundo trazada en la sucesión e interconexión de los textos que hablan de la realidad metafóricamente. No obstante, algún estudioso (Boulter 2001) ha resaltado que Borges, sus cuentos, se resisten vigorosamente a toda catalogación o intento de extraer consecuencias universales de ellos, a ser más que simulacros. Parece que no hay otra forma de aproximarse al universo, si no es entreviéndolo parcial y pobremente, con instrumentos relativos y deficientes. Aun más, Dove (2007) realiza en su trabajo un exhaustivo estudio de las supuestas conexiones del lenguaje (la metáfora) con una incierta realidad o mensaje; conexiones que niega. Es como la Cábala (Gutiérrez 2010), un instrumento que acumula infinitas interpretaciones de un texto (se diría que incluso suplantando al propio texto, lo cual, algunos antiguos hermeneutas del judaísmo expresaron señalando que el total de las interpretaciones de la Torah era la refutación de la Torah) y que, a su vez, conecta intertextualmente todos los textos. El infinito se aprehende con el infinito, que son todas las cosas pero ninguna en concreto, y por tanto, no refiere a nada. Aun más, no hay nada que aprehender. No hay más que lecturas, relecturas y una interminable baraja de interpretaciones, muchas contradictorias (tanto es así, que en la Cábala no hay lugar para la herejía: la ortodoxia es todas las interpretaciones). La Cábala no representa la realidad, sino que la suplanta por la red de las interpretaciones que no refieren a realidades. Es un instrumento exegético que se usa sobre el propio lenguaje, lejos de la «realidad». La Cábala se ha descrito como un tipo especial de teoría sobre el texto, aun más, como una hermenéutica o retórica de segundo grado, un método para producir interpretaciones (Bold 2005, pp. 118-121). Asimismo, la Cábala se asemeja a otro tópico borgeano, el del laberinto, que es una suerte de anónima red de palabras que invocan a más palabras.

No hay lugar para la hermenéutica que pretende hallar significados o mensajes más allá del texto (borgeano). En Borges se da un juego de simulacros que intentan aprehender el universo pero fracasan continuamente. El universo y los instrumentos de su aprehensión se resisten vivamente a dar respuestas. Porque, en sentido estricto, en realidad, no hay respuestas. Esto es muy evidente en el relato «El Aleph», en el que se «describe» el universo en varios planos (el propio Aleph, el largo e inacabado poema de uno de los personajes, la conmoción producida en el protagonista), sugiriéndolo bella pero deficitariamente. Su imposibilidad para decir en una única palabra, fuera de esa realidad de textos que se agolpan en torno a supuestos significados, es signo de la precariedad del lenguaje y, aun más, de la disuelta identidad de quien lo escribe o habla: «Así como el lenguaje está siempre supeditado a contingencias, el ser humano también lo está, puesto que se halla inseparablemente unido al lenguaje y, consiguientemente, su yo tampoco es una entidad estable» (Sagastume 2011, p. 274).

Finalmente, lo más trágico de la posición borgeana es que en él anidaría un pathos platónico, que intenta mantener que todo tiene un modelo ideal; pero lo cual, trágicamente, no puede ser creído. Es como estar en Derrida pero anhelar a Platón. Según Juan Nuño (1986), en este sentido, Borges sería una especie de 
Platón pero como si Platón hubiera perdido su fe en las ideas, aunque las siga necesitando para desenvolverse en un mundo deshecho en significantes que ya no se refieren a nada fuera de sí. Borges ostenta la estoica posición de quien acepta la deleznable «realidad» de la pared de la caverna, sin que ya exista nada externo a la caverna ni otra iluminación posible. Es esta suerte de platonismo desencantado la honda tensión que permea en Borges y muchos de sus textos, un platonismo profesado por Borges, pero del que en realidad descree ${ }^{8}$.

\section{El véRtigo}

En su extraño escepticismo platónico, Borges insiste a menudo en aquello que amenaza todos los órdenes, en el constante acecho de las sombras y espejos de la caverna a las hieráticas ideas del mundo superior. Así, en sus dos ensayos dedicados a la famosa paradoja de Aquiles y la tortuga forjada por Zenón, discípulo de Parménides («La perpetua carrera de Aquiles y la tortuga» $\mathrm{y}$ «Avatares de la tortuga») (Borges 1999b), concluye afirmando que acaso este problema existe como una de tantas fisuras por las que el orden del mundo amenaza con desintegrarse. Hay, viene a decir, una suerte de guiños en el mundo que nos sugieren la falsedad de toda construcción armónica y total del universo, y que insinúan la constante amenaza de un caos. Las paradojas de Zenón serían como un corrosivo que actuara mermando los pilares del cosmos. En realidad, afirma Juan Nuño en su magnífico libro La filosofía en Borges (1986), Borges incurre en algunos equívocos a partir de una malinterpretación esencial de lo que Zenón quiso mostrar y que se refiere, ante todo, a una determinada concepción matemática del espacio que debía ser refutada por incongruente con el mundo. Pero esto es lo de menos. Lo importante es la alineación de Borges en ese lugar común de toda literatura fantástica que juega a no creerse el mundo, llenándolo de ambigüedades y sospechas. Hablar, escribir, son ya sospechar. Y «El lenguaje y la literatura, (...), revelan esa posibilidad, esa fisura del mundo que sólo a través de la palabra, de la ficción, puede ser sentida o intuida» (Amaro 2005, p. 184).

Borges tiene, además, dos cuentos titulados «La lotería en Babilonia» y «Tlön, Uqbar, Orbis Tertius» (Borges 2002) en los que ocurre una disgregación del universo que se confunde con sus múltiples variables y con las fatigosas

8 Sostiene, sin embargo, Rodríguez Martín (2008, pp. 237-239), que lo que existe en Borges no es ni platonismo ni nominalismo, ni apuesta sólo por lo arquetípico o por lo concreto, sino una síntesis de ambos que sigue el modelo representado por Schopenhauer. Ello para desembocar en la afirmación de que «(...) podríamos decir que Borges afirma la individualidad como parte intensional de lo universal — egotismo- y, paralelamente, niega su existencia en beneficio de una identificación con los demás seres disolviéndolo en la Nada/ Voluntad —egocidio—» (Rodríguez MARTín 2008, pp. 242). 


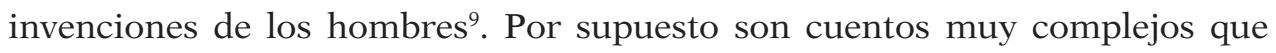
pueden y deben ser analizados con mayor profundidad, como hace Nuño, pero nuestro interés no es sino corroborar la idea de que Borges jugaba, una vez más, a no creerse demasiado el universo. Con el trasfondo del pesimismo de Schopenhauer, Borges arremete contra la ordenación platónica del mismo que él sugiere y anhela creer.

El hombre sería una suerte de bibliotecario en esa biblioteca que es el universo, en la conocida metáfora borgeana trazada en el cuento «La biblioteca de Babel» (Borges 2002). ¿Puede seguir siendo llamado «orden» un orden que no puede ser comprendido por el hombre? En cualquier caso, las explicaciones últimas y la búsqueda de lo fundamental nos conducen a husmear en el insondable abismo de la divinidad. Ésta es, precisamente, como la imagen de lo divino en Kafka, un ámbito sagrado inalcanzable y lejano que casa con el tema luterano del Deus Absconditus o la perspectiva de cierto judaísmo (la Cábala). A la esencia sagrada se llegaría precisamente acabando de derruir todo orden y armonía, como ocurre con los koan en el budismo zen.

«Funes el memorioso» (Borges 2002) y «El Aleph» (Borges 1999a) comparten un mismo punto de vista. Se trata de las consecuencias de un universo sin especies, en el que todo fueran individuos singulares (el universo de un nominalista). Existe en el hombre la capacidad de abstraer de tanta diversidad lo esencial, lo cual le vale para pensar, hablar o hacer ciencia. Borges imagina, en el caso de Funes, un sujeto cuya formidable memoria es capaz de almacenar absolutamente todos los detalles de un universo que se torna, ante su maravillosa capacidad, una catarata de sensaciones que pierden su conexión. De ahí que sea imposible imaginar ni siquiera que un perro es un perro, puesto que no es el mismo animal, para la memoria de Funes, a una hora o a otra, ya que han cambiado detalles que para su infalible percepción son fundamentales. Cada hoja de un árbol es un objeto distinto y bien diferenciado de las demás hojas, por lo que resultaría imposible concebir todas las hojas en un conjunto llamado «árbol». Funes es, debido a su extraño poder, un idiota al que el universo conmociona continuamente sin que él pueda entender, en realidad, nada del mismo. Una memoria infalible es inútil y absurda, y con ella el universo se torna una confusa y caótica pesadilla. Funes es capaz de pasar días enteros recordando otros días pasados segundo a segundo, repitiendo minuciosamente en su mente lo acaecido.

Creemos que de un modo semejante, el universo en «El Aleph» es presentado de esta manera. En un punto, todo coincide. No sólo las cosas, sino los distintos tiempos y fases de las cosas, como hemos señalado en líneas anteriores, son contemplados en el fantástico Aleph como una aturdidora procesión que muestra

9 El valor del relato «Tlön, Uqbar, Orbis Tertius» para clarificar la relación de Borges con la filosofía resulta crucial, como afirma y muestra en su artículo FERNández (2000). Filosóficamente, señala STEWART (1996) parece ser una reducción al absurdo del subjetivismo idealista inspirado en Berkeley. El mundo queda pulverizado y desaparecido en cuanto realidad fuerte. 
el universo tal como es en cuanto a los singulares (en relación con el «mundo» del nominalista). Tal cascada no puede sino activar una espantada descreencia. Surge la inquietud acerca de si tal profusión puede ser real, y surge el horror cuando el mundo de los arquetipos y esplendores (de las especies como entes reales según los «realistas» medievales) desaparece del conocimiento.

\section{CONCLUSIÓN: FINITUD Y NADA}

Cuando el protagonista de «El inmortal» (Borges 1999a) convierte en realidad su aspiración, se ve abocado a algo fatal. Porque los inmortales, tras un lapso de tiempo que puede abarcar siglos, se tornan insensibles, inactivos y perezosos como vegetales o piedras. Porque la inmortalidad descrita por Borges es una prolongación en el tiempo de la vida humana (no equivalente a una eternidad, en la que coincidirían todos los tiempos), una persistencia en el ente que, paradójicamente, acaba negando ostensiblemente al ser.

Borges atribuye al ser la característica ontológica del no ser. No existe el yo porque estamos ligados al instante y a la discontinuidad del tiempo pero, simultáneamente, el mundo se nos da por entero en cada instante, en cada representación, en cada lectura (Rodríguez Martín 2008, p. 242).

Una corta vida mortal no tiene tiempo de saciarse de este desfile sin sentido de las apariencias, por lo que puede mantener ilusiones, albergar esperanzas, proyectar un futuro, disfrutar del momento y darse al placer. Todo esto deja de tener valor para un inmortal, que acaba sumergiéndose en un tedio atroz de confusos recuerdos y olvidos. Los inmortales de Borges amplifican la existencia tal como la conocemos (la finita existencia humana), para descubrir que la finitud mitiga los dolores y concede placeres que para un inmortal acabarían siendo aburridos. El propio inmortal es llevado a reconocer la condición finita del hombre, y a acabar deseando la muerte. La inmortalidad hace ver, por una suerte de prolongación o reducción al absurdo, que nos caracteriza sobre todo la durabilidad, la finitud y la contingencia.

Aun peor. Ni siquiera la memoria sería capaz de obrar confiriendo un sentido cierto a tanta diversidad caótica que corroboran los inmortales, ya que si existe el recuerdo, existe también el olvido.

No solo que la memoria es falible y, por lo tanto, hace imposible el que el ser recuerde absolutamente todas las contingencias a las que se ha enfrentado a lo largo de su vida y que han forjado su yo, sino que ese 'yo de conjunto', es decir, ese yo innato, no existe sino que cambia permanentemente (Sagastume 2011, p. 274).

El efecto de la inmortalidad sería sumirnos en el horror esencial de un universo que persiste desmembrado y mudo (el lenguaje es un afán imposible para los inmortales, alguno de los cuales opta por callar). Todo se disolvería en una sucesión de espejos que reflejan espejos, en un fatigoso laberinto sin 
centro ni hilo de Ariadna, en un torbellino de tiempo que se tragaría todo despiadadamente. El inmortal vería iniciarse mundos, aplanarse montañas, salir formas grotescas de las aguas esenciales, volver formas grotescas a las aguas esenciales, el fuego tornarse hielo, sucederse los sistemas solares, nacer y morir las estrellas. Y no ver más que esto, a cualquier ángulo que mirase, sin palabras ni respuestas, sin poderse dirigir a nadie. Como en el cuento de Borges o en la religión budista, el hombre solo ante el remolino de una creación sin creador, desearía disolverse definitivamente en la nada.

\section{REFERENCIAS BIBLIOGRÁFICAS}

Amaro, L. (2005). «Borges: una poética de la identidad personal», Aisthesis, 38, pp. 180191.

Báez, F. (2003). «¿Borges, filósofo?», A Parte Rei, 25. http://serbal.pntic.mec. es/ cmunoz11/filoborges.pdf

Bold, S. (2005). «Borges, inventor of the Pensées; or la busca de Pascal», Romance Quarterly, 42: 2, pp. 115-134.

Borges, J. L. (1998). Inquisiciones. Madrid: Alianza editorial [Edición original 1925].

Borges, J. L. (1999a). El Aleph. Madrid: Alianza editorial [Edición original 1949-1974].

Borges, J. L. (1999b). Discusión. Madrid: Alianza editorial [Edición original 1932-1964].

Borges, J. L. (2002). Ficciones. Madrid: Alianza editorial [edición original 1944-1974].

Bosteels, B. (2007). "The truth is in the making. Borges and pragmatism», Romanic Review, 98: 2/3, pp. 135-152.

Boulter, J. S. (2001). "Partial Glimpses of the infinite: Borges and the simulacrum», Hispanic review, 69: 3, pp. 355-377.

Camauer, S. (2007). «Borges, discípulo explícito y virtual de Nietzsche», Instantes y azares. Escrituras nietzscheanas, 4-5, pp. 145-148.

Camauer, S. (2009). "La 'ficcionalización' de la realidad desde las perspectivas de M. Heidegger y J. L. Borges», Ágora. Papeles de filosofía, 28: 2, pp. 143-155.

Castany, B. (2005). «El escepticismo en la obra de Jorge Luis Borges», Konvergencias, Filosofía y Culturas en diálogo, 10. http://www.konvergencias.net/borgesescep.htm

Castillo, J. L. (2003). «Pierre Menard and the school of the skeptics», Hispanic Review, 71: 3, pp. 415-428.

Cofré, J. O. (1995). «Fundamentos y análisis de estética fenomenológica (Leonardo y Borges, dos modalidades de la ficción)», Cuadernos salmantinos de filosofía, 22, pp. 315-341.

Derrida, J. (2007). La diseminación, Madrid, Fundamentos. [Edición original 1975].

Dove, P. (2007). "Metaphore and image in Borges's "El Zahir" ", Romanic review, 98: 2/3, pp. 169-187.

Earle, P. G. (2003). «In and Out of Time. (Cervantes, Dostoevsky, Borges)», Hispanic review, 71: 1, pp. 1-13.

Fernández, E. (2000). «Postales de Uqbar: Borges, Berkeley y los problemas de la percepción», Agora Philosophica: Revista marplatense de Filosofía, 1 (2), pp. 59-77.

Gutiérrez, V. (2010). "Mystical Laws. Borges and Kabbalah», CR: The new centennial review, 9: 3, pp. 137-164 y pp. 288-289.

Jill Levine, S. (2012). «Borges sobre la traducción», Teoría de la Educación: Educación y Cultura en la sociedad de la información, 13: 1, pp. 9-39. 
Lema-Hincapié, A. (2002). «Borges y la filosofía occidental: algunos momentos de la crítica», Praxis filosófica, 14, pp. 99-114.

Magnavacca, S. (2007). "Neoplatonismo medieval en Borges», Anales del Seminario de Historia de la Filosofía, 24, pp. 67-83.

McDermid, D. (2005). «La poesía como un preludio a la filosofía: algunas reflexiones sobre un poema tardío de Borges», Dianoia (México), 50 (54), pp. 123-140.

Nuño, J. (1986): La filosofía en Borges. México: FCE.

Pfeiffer, M. L. (1999): «El tiempo en Borges. Una reflexión fenomenológica sobre la memoria», Diálogo filosófico, 15: 2, pp. 245-254.

Premat, J. (2003): «El último Borges: un Yo plural y una sola sombra», Pandora. Revue d'etudes hispaniques, 3, pp. 197-210.

Presas, M. A. (1999): «El arte como saber», Revista latinoamericana de filosofía, 25: 1, pp. 129-140.

Radford, G. P. (2005): «Structuralism, post-structuralism, and the library. De Saussure and Foucault», Journal of Documentation, 61: 1, pp. 60-78.

Rodríguez Martín, M. C. (2008): «El canto del ruiseñor. Aproximación a las nociones de universal y particular en Borges», Thémata. Revista de filosofía, 40, pp. 235-244.

Sabot, Ph. (2006): «Los juegos del espacio y del lenguaje: heterotopía, isotopía, caligrama», Aisthesis, 40, pp. 33-44.

Sagastume, J. R. (2011): «"El inmortal” de Jorge Luis Borges. El Yo, Aleph absolutos y vocabularios finales», Revista de Filosofía, 67, pp. 269-289.

Scavino, D. (2007): La filosofía actual. Pensar sin certezas. Buenos Aires: Paidós.

Schultz, M. (1992): «Borges y la filosofía del tiempo», Daímon, 5, pp. 109-122.

Stewart, J. (1996): «Borges and the refutation of idealism: a study of "Tlön, Uqbar, Orbis Tertius"», Ideas y valores. Revista Colombiana de Filosofía, 101, pp. 64-99.

Tudela, A. (2002): «Gilles Deleuze y el pensamiento del cinematógrafo», Revista de Filosofía, 42, pp. 7-37.

Urroz, E. (2005): «Libertad y subjetividad en Borges», Revista de la Universidad de México, 11, pp. 78-88.

Zavadivker, N. (2008): «Borges y la Metafísica», A Parte Rei, 58. http://serbal.pntic.mec. es/ cmunoz11/nicolas58.pdf

[Artículo aprobado para publicación en diciembre de 2016] 